\title{
Analysis and Solution for Fallout Repair and Tunneling in Sandy Soil Conditions for a Wine Cave in Southern California
}

\author{
Scott Ureel $^{1, *}$, Ron Skaggs ${ }^{1}$, Kerry Cato ${ }^{2}$ \\ ${ }^{1}$ Condor Earth Technologies, United States \\ ${ }^{2}$ Cato Geosciences, United States
}

Copyright $\bigcirc 2018$ by authors, all rights reserved. Authors agree that this article remains permanently open access under the terms of the Creative Commons Attribution License 4.0 International License

\begin{abstract}
The design and construction of wine caves can be difficult due to low ground cover, weak rock or soil, presence of sand and complicated by the elaborate curves and labyrinth-style floor plans. This paper will focus on southern California's first wine cave in the Temecula wine region that was constructed by mining techniques. An excavation procedure was needed to reinstate tunneling excavation at the Oak Mountain Winery in Temecula, CA USA after a fallout with an estimated 6.1 meter diameter and 6.71 meters overburden. Sandy soils with low cohesive properties and low saturation have created difficult tunneling and safety conditions. The proposed excavation sequence was divided into four stages using spilling if needed until less sandy or stronger material was encountered The following analyses were performed to provide supporting calculations and information to provide safe tunnel excavation conditions as required by mining regulatory oversight. Analyses using cellular concrete for fallout conditions were also modeled. Results, recommendations and conclusions are presented.
\end{abstract}

Keywords Wine Cave, Sandy Excavation, Numerical Modeling, Fallout, Tunnel

\section{Introduction}

Over the last three decades, the California wine industry has experienced a growing interest in the development of wine caves and other underground structures. Wine Caves help maintain the correct humidity and temperatures for wine barrel storage, create beneficial land use and create marketing venues and opportunities for wineries. Hence, an increasing number of wine caves are being constructed throughout California.

Safely tunneling through partially stable soft ground conditions can be very difficult. Sandy soils can present issues with shotcrete adhesion, unstable ground and roof fallout potential. Recently, these issues were experienced while tunneling the Oak Mountain Winery wine cave in Temecula, CA USA. This paper presents the results of a geological and geotechnical engineering study performed in order to provide conclusions and recommendations for the remediation of fallout conditions and the presence of sandy soil in a new underground wine cave (tunnel) complex adjacent to the existing Oak Mountain Winery. Previous investigations and studies relating to sandy soil tunneling and underground excavations can be found in references [1], [2] and [3]. The following analyses were performed to provide supporting calculations and information to ensure safe tunnel excavation conditions. Analyses using cellular concrete for fallout conditions were also modeled. Further information regarding cellular concrete can be found in Hamad [4] and Kim, et al [5]. Results, recommendations and conclusions are presented.

\section{Geological and Tunnel Background}

The significant findings from the geological investigations before and during tunnel construction included surface soil overlying sandstone and siltstone of the Pauba Formation. The sandstone was logged as slightly cemented and generally thinly bedded and ranged from soft to low hardness. It was also moderately to severely weathered, and widely to closely fracture. Blow counts using a California Modified sampler in the sandstone ranged from 29 to 84 . Sandy soils with low cohesive properties and low saturation created difficult tunneling and safety conditions prior and subsequent to the fallout event.

After sandy conditions were recognized, probe testing was performed at the Oak Mountain Winery using a 6.8 kilograms ( $15 \mathrm{lbs}$. hammer) with 1.27 centimeter ( $1 / 2 \mathrm{inch})$ diameter 1.524 meter (5-feet) long coupled rods and this 
was driven with an electric percussion drill head from the ground surface to the approximate tunnel depth. This pseudo-hand held SPT device was necessitated due to the presence of and existing vineyard overlying the tunnel and the inability to use a standard drill rig. The site plan for probe locations is shown in Figure 1 where the highlighted light blue area indicates fallout section. Probe numbers 2, 3, 11, 12 along Tunnel $\mathrm{A}$ indicate an advancement rate between 36.1 and 912.1 seconds/meter in the longitudinal direction of tunnel advancement. Probe 12 (at the mining face beyond the fallout) has the slowest advancement rate of 912.1 seconds/meter and indicates better mining ground conditions.

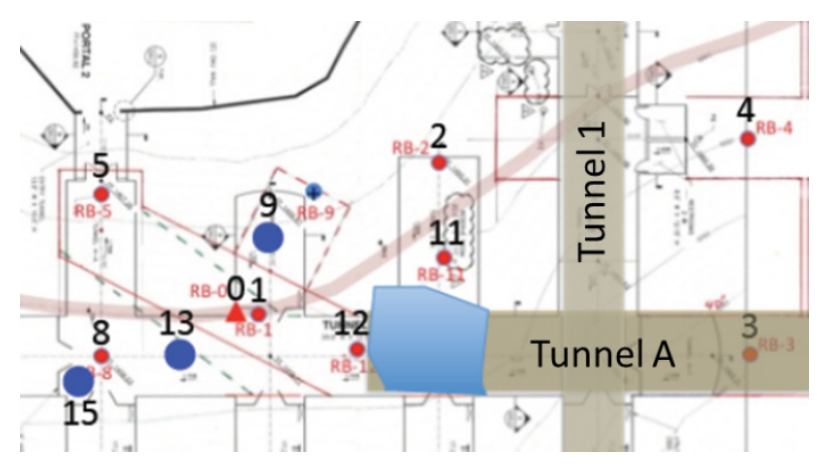

Figure 1. Probe rod locations

The longest tunnel, Tunnel A, connects between four other tunnels, and is approximately 6.1 meters width $\times 3.9$ meters height. The tunnels were excavated full-face using the sequential excavation method (SEM) of tunneling. The maximum tunnel advance distance prior to initial liner installation will be a function of the "stand-up time" based on observations on site, the length of time that the ground can remain unsupported, and the tunnel contractor's means and methods. The initial shotcrete layer (5.08 centimeters of shotcrete) was applied to the new open ground of the tunnel perimeter each day. The second sub-layer of initial shotcrete layer (approximate 2 inches of shotcrete with one layer of welded wire fabric (WWF) 4 x 4 - W4.0 x W4.0 WWF) was installed closely behind the tunnel working face based on the construction schedule. The contractor advanced the tunnel and placed the initial shotcrete liner over the exposed ground as specified. The design of liners and structural system were confirmed during construction based on observed overburden, weathering conditions, and geologic materials.

In Tunnel A, a fallout of sandy material with an estimated 6.1 meters diameter and 6.71 meters overburden occurred while excavating the face heading (Figure $2 \mathrm{a}$ and $2 b)$. The fallout and sandy conditions caused interruption in the construction of the tunnel and exhibited safety hazards. An excavation procedure was needed to reinstate tunneling excavation at the Oak Mountain Winery in Temecula, CA. Following the fallout and sandy soil conditions, a mitigation procedure was created to repair the fallout section of the tunnel with cellular concrete (Figure $3 \mathrm{a}$ and $3 \mathrm{~b}$ ) and enhance the sequential excavation method using the diagram provided in the discussion section of this paper. For further background information please refer to Condor geotechnical study [6].

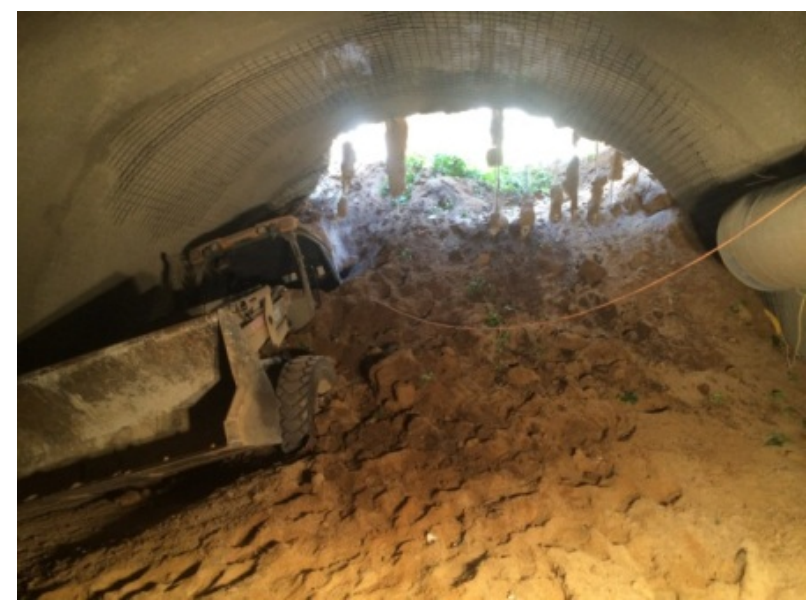

Figure 2a. Looking at sand fallout along tunnel bearing.

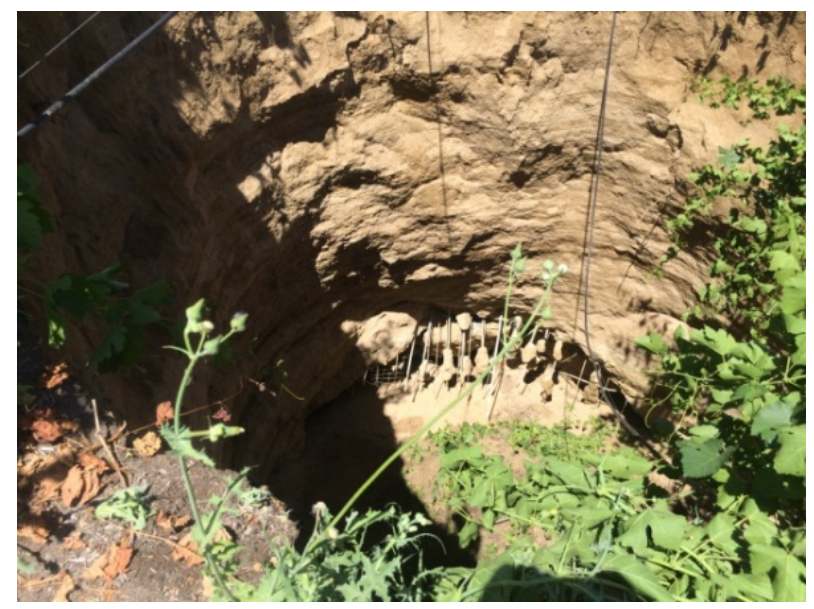

Figure 2b. Looking down into the tunnel; vine vegetation and wires from trellises on the surface fell into the opening.

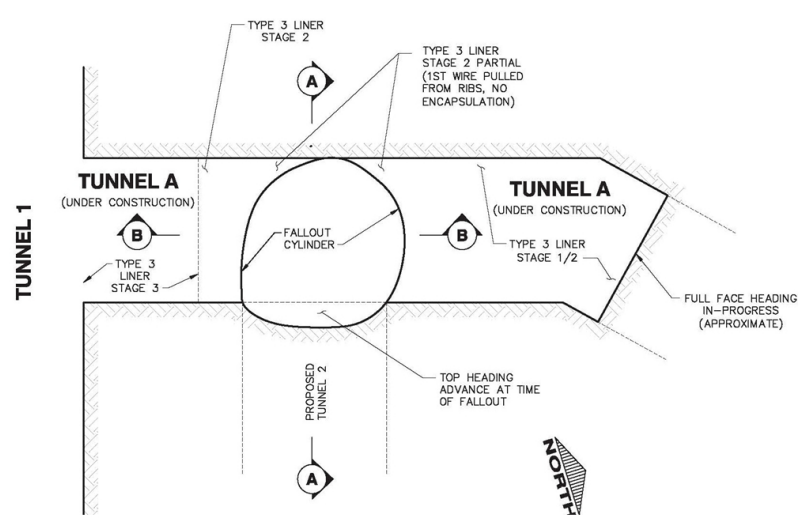

Figure 3a. Site plan of fallout area 


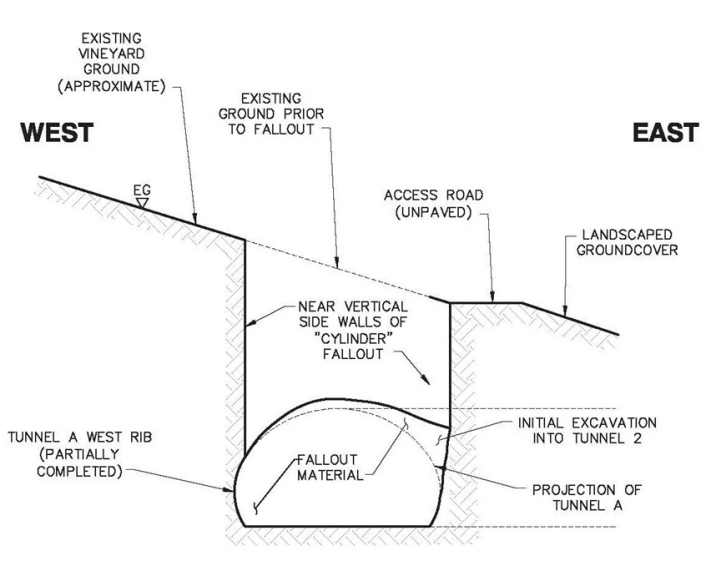

Figure 3b. Cross section of fallout in Tunnel A.

\section{Data Analysis}

In order to fully understand the soil and tunnel liner conditions, the Rocscience finite element analysis program Phase 2 [7] was utilized to model the use of cellular concrete, ground stress, displacement and tunnel liner performance. The tunnel liners and soil properties were modeled using the Mohr-Coulomb failure criteria and plastic conditions. The liner structural design approaches described in Federal Highway Administration [8] were followed during the analyses as well as the in-situ properties Sheorey [9]. Modeling techniques mentioned in Vlachopoulos and Diederichs [10] were utilized. The following section will discuss the input parameters and results of the models.

\subsection{Material Properties}

Based on site observations, previous investigations, and more recent probe data, the ground conditions above the proposed crown of Tunnel A appeared to consist of material properties with almost no cohesion and a friction angle of 35 degrees. The low cohesion and friction angle were used to simulate field conditions of sandy material for the weaker material anticipated for the actual range of likely ground conditions. Since the tunnel conditions experienced a fallout indicating low horizontal stresses, a $\mathrm{K}$ ratio value of 0.33 was utilized. Concrete properties were collected from laboratory results. The material properties compiled are shown in Table 1 below.

\section{2. "Q” System Estimation for Liner Support}

Although the Q System Barton et al, [11] was developed for rock blocks and rock like conditions in tunnels, the $\mathrm{Q}$ System analysis provided an estimate for reinforcement needed for tunnel support in weak rock prior to encountering sandy conditions. A sensitivity analysis was performed to understand how the results differed relating to stress conditions, height and tunnel span and alteration of the material. All Q values calculated provided similar results (within the range of the sensitivity of the analysis) regarding reinforcement and tunnel liner thickness. All values suggested the need for a fiber reinforced shotcrete liner with a thickness of 15.24 centimeters or greater. Since the project plans require the use of WWF, the objectives of the fiber reinforced shotcrete were achieved. The following sections provide the analyses performed for sandy soil conditions since the Q system would be not applicable.

\subsection{Stress and Displacement Conditions}

From figure 4, the stresses applied at the tunnel crown are approximately 129.2 to $157.9 \mathrm{kPa}$ in the vertical direction. The estimated stresses at the tunnel crown exhibit a radial stress of $12.0 \mathrm{kPa}$ indicating the material at the tunnel crown is in tension.

Figure 5 displays the vertical displacement calculated by Phase 2 modeling for a 6.1 meter wide tunnel with no liner. From the plot, the displacement at the crown of the tunnel is very large (18.3 meters) indicating the model has failed and the material above the crown has fallen out. The model indicated the soil close to FOS $=1$ around the tunnel which is expected with no liner; however, when modeling a tunnel with smaller width the factor of safety at tunnel crown is above one indicating stable conditions for excavation.

Table 1. Summary of Properties

\begin{tabular}{|c|c|c|c|c|c|c|c|c|}
\hline \multirow{2}{*}{$\begin{array}{c}\text { Excavation } \\
\text { According to } \\
\text { Drawing }\end{array}$} & $\begin{array}{c}\text { Unit } \\
\text { Weight } \\
(\mathrm{kN} / \mathrm{m} 3)\end{array}$ & $\begin{array}{c}\text { Friction } \\
\text { Angle } \\
(\mathrm{deg})\end{array}$ & $\begin{array}{c}\text { Cohesion } \\
(\mathrm{kPa})\end{array}$ & $\begin{array}{c}\text { Modulus } \\
\text { of } \\
\text { Elasticity } \\
(\mathrm{kPa})\end{array}$ & $\begin{array}{c}\text { Unit } \\
\text { Weight } \\
(\mathrm{kN} / \mathrm{m} 3)\end{array}$ & $\begin{array}{c}\text { Compressive } \\
\text { Strength } \\
(\mathrm{MPa})\end{array}$ & $\begin{array}{c}\text { Liner } \\
\text { Thickness } \\
(\mathrm{cm})\end{array}$ & Reinforcement \\
\hline 0 & 18.9 & 35 & 0.239 & 34466 & 23.6 & N/A & N/A & N/A \\
\hline 1 & 18.9 & 35 & 0.239 & 34466 & 23.6 & 3.5 & 5.08 & None \\
\hline 2 & 18.9 & 35 & 0.239 & 34466 & 23.6 & 6.9 & 10.16 & 1 Layer - WWF \\
\hline 3 & 18.9 & 35 & 0.239 & 34466 & 23.6 & 13.8 & 15.24 & 2 Layer - WWF \\
\hline 4 & 18.9 & 35 & 0.239 & 34466 & 23.6 & 27.6 & 20.32 & 2 Layer - WWF \\
\hline
\end{tabular}




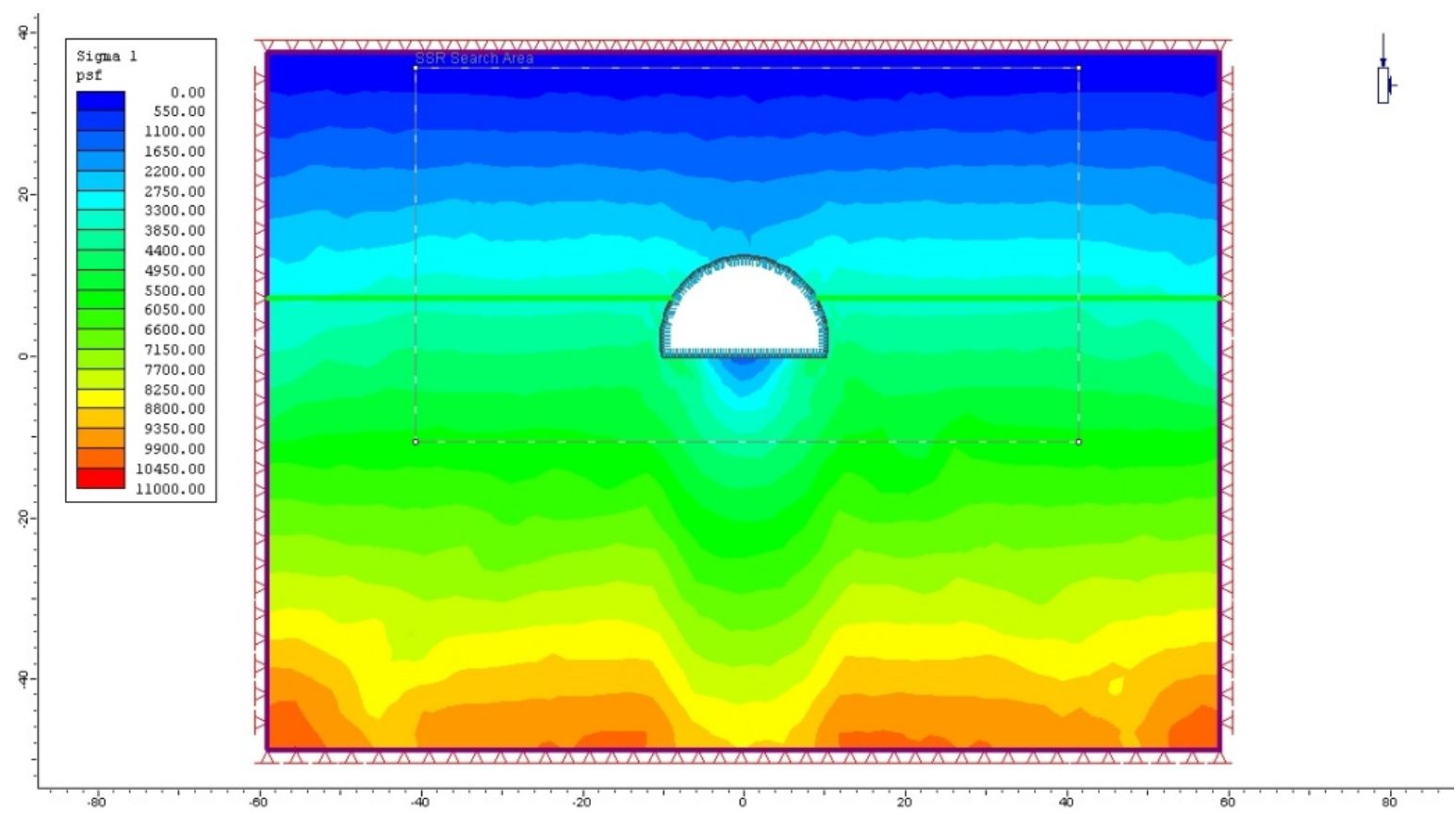

Figure 4. Sigma 1 (Vertical Stress) in sandy soil

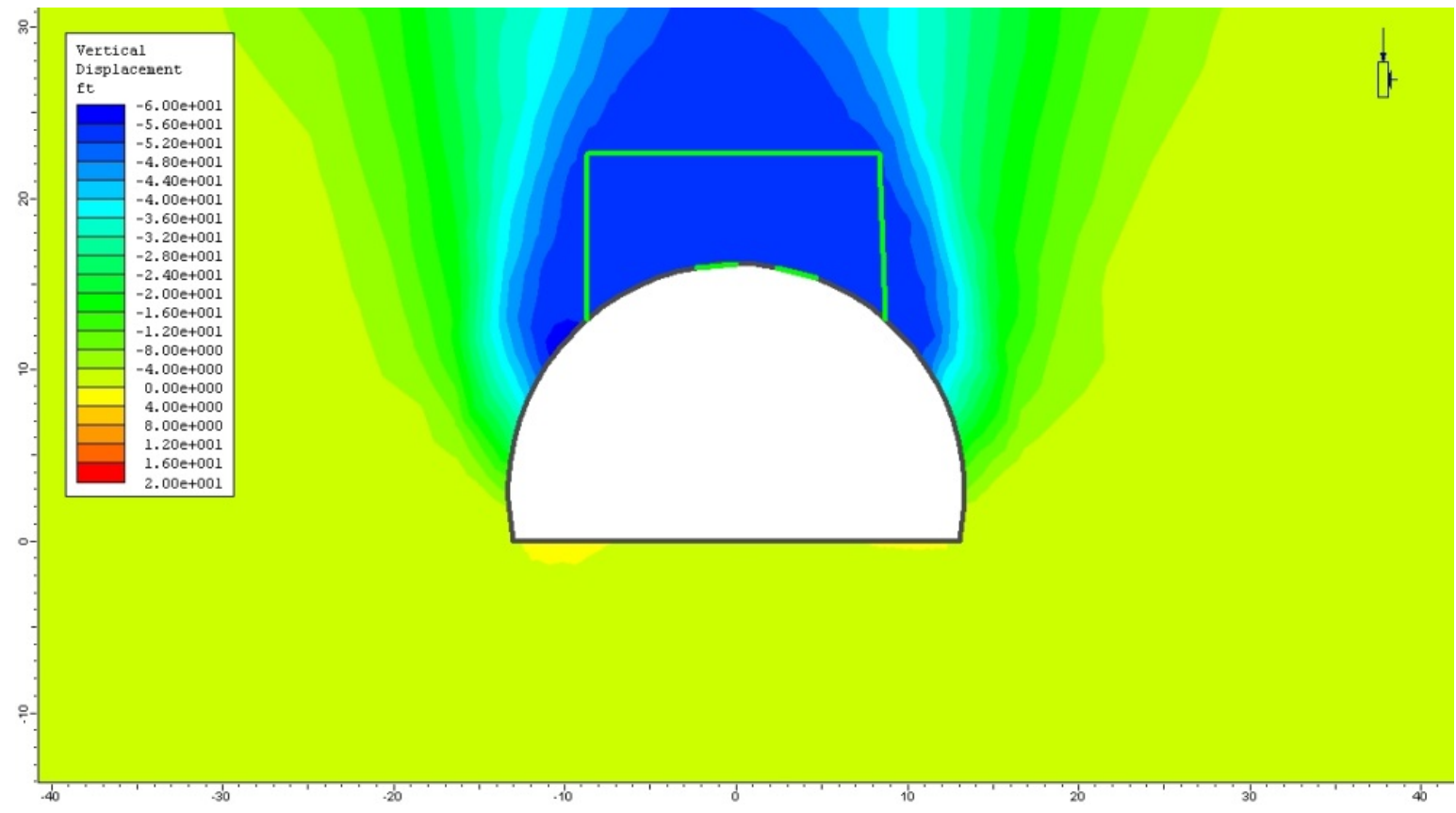

Figure 5. Vertical displacement for a 6.1 meters wide tunnel with no liner using basic factor of safety calculations.

\subsection{Four Stage Excavation Sequence Model}

Four models (for of the excavation stages) were constructed to examine the liner and liner reinforcement shear and moment capacities and the soil displacement. The materical properties were assumed as shown in Table 1. The final shotcrete wall was a Type III liner, 20.32 centimeters thick with two layers of welded wire fabric (WWF) reinforcement. The first stage utilizes a 5.08 centimeters thick shotcrete wall with no reinforcement. The second stage adds 5.08 centimeters of shotcrete with one layer $4 \times 4 \mathrm{WWF}$ to maintain a shotcrete wall thickness of 10.16 centimeters. The third stage of the excavation adds 2 inches of shotcrete for a total of 15.24 centimeters as well as a second layer of $4 \times 4$ WWF. Stage four of the excavation sequence adds final 5.08 centimeters shotcrete layer totaling to 20.32 centimeters. The following plots for each excavation state are the shear and moment capacity plots for each liner and reinforcement layer (Figure 6-9). Table 2 exhibits a summary of results and factor of safety for the reinforcement WWF as well as the shotcreteed structural liner. 

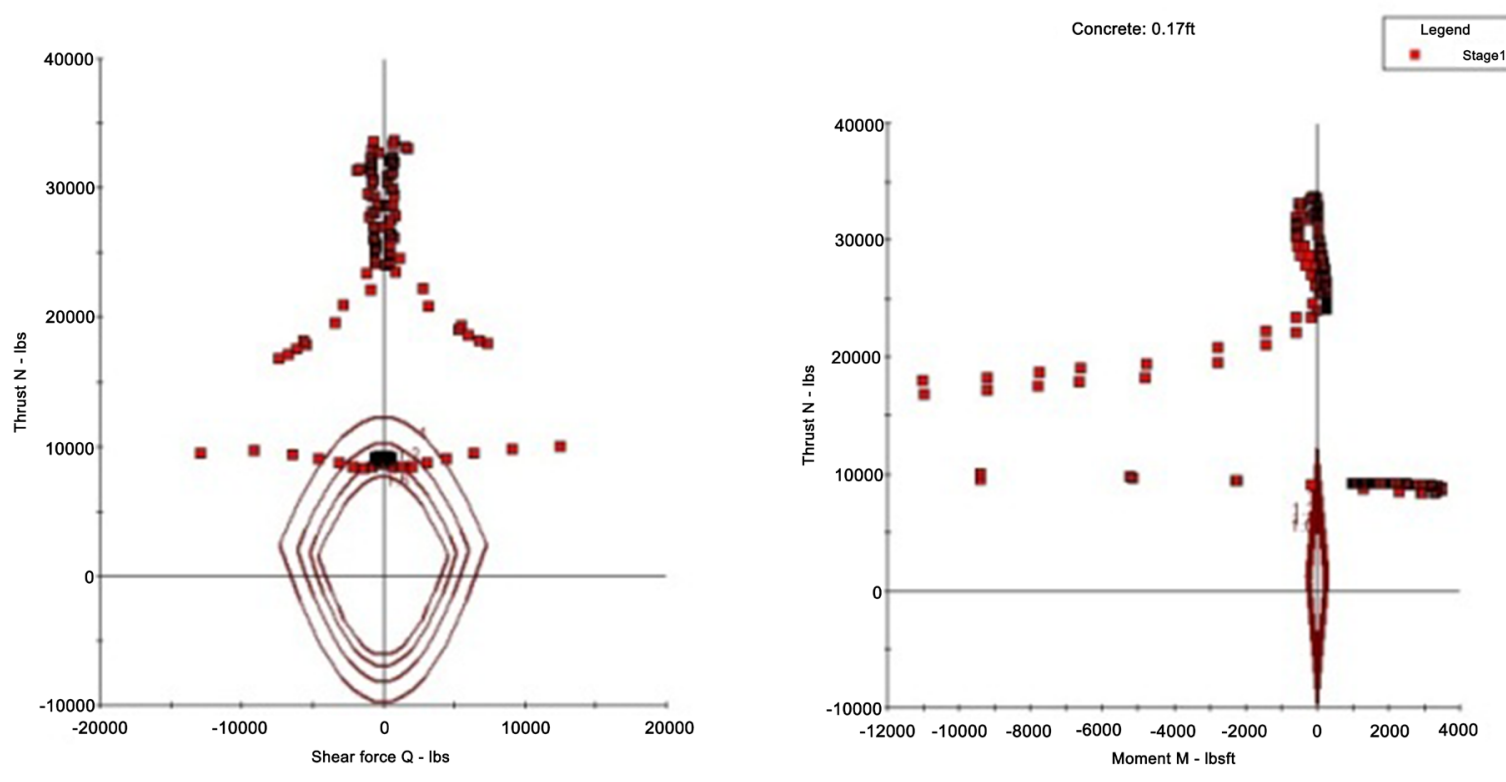

Support Element $2^{\text {nd }}$ liner

Figure 6. Shear/Moment Diagram Stage 1
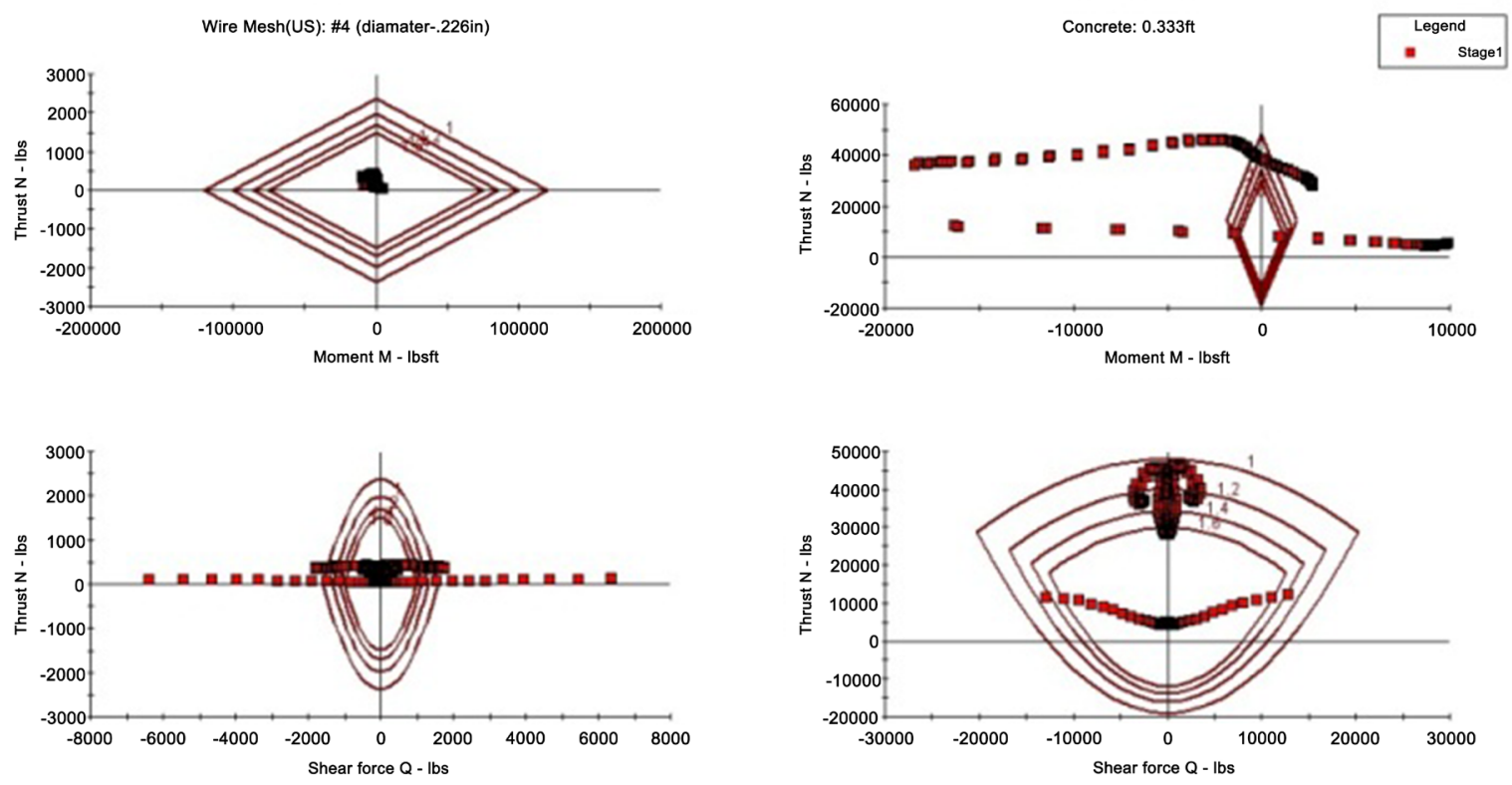

Support Element 4" liner

Figure 7. Shear/Moment Diagram Stage 2 

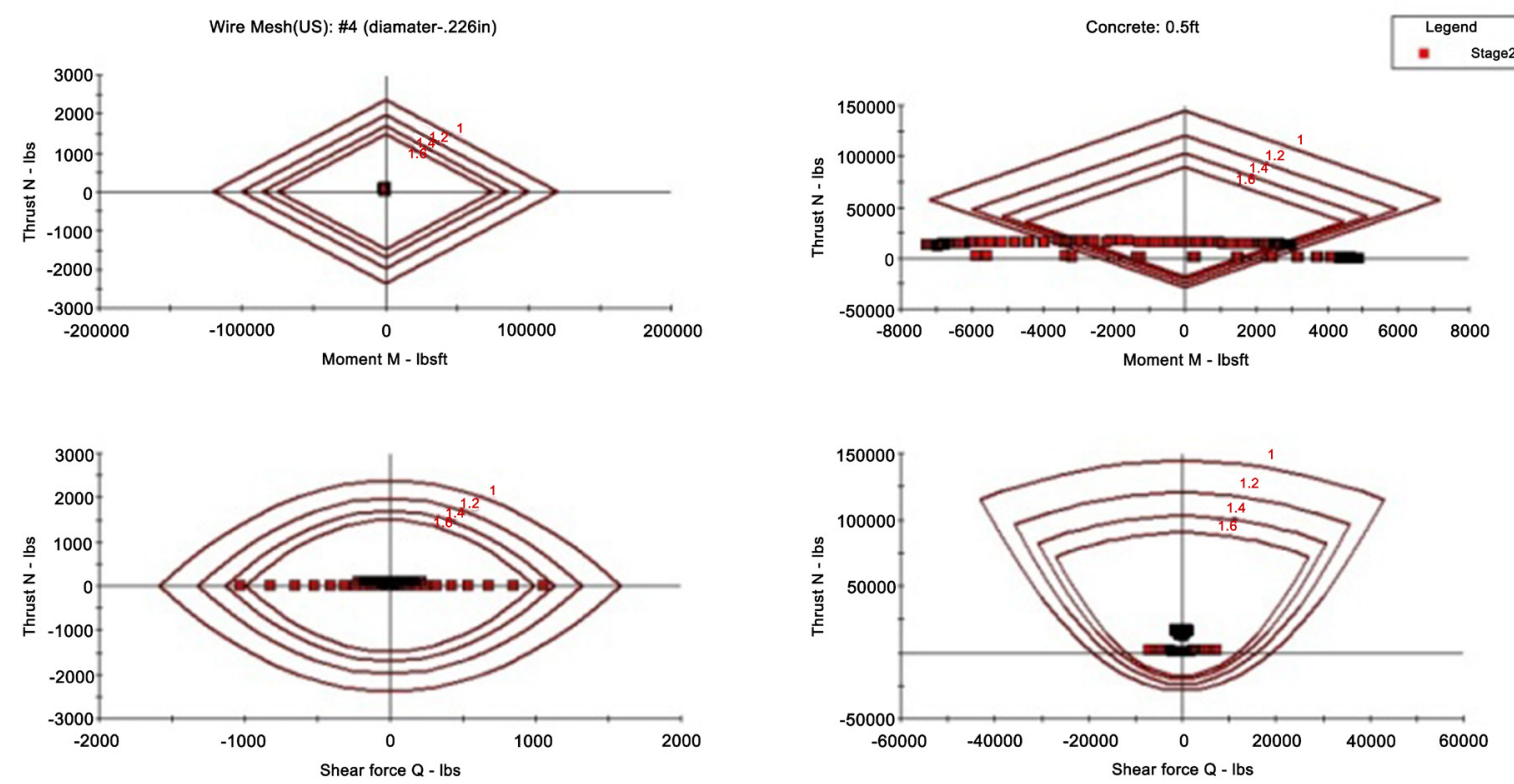

Support Element 6" liner

Figure 8. Shear/Moment Diagram Stage 3
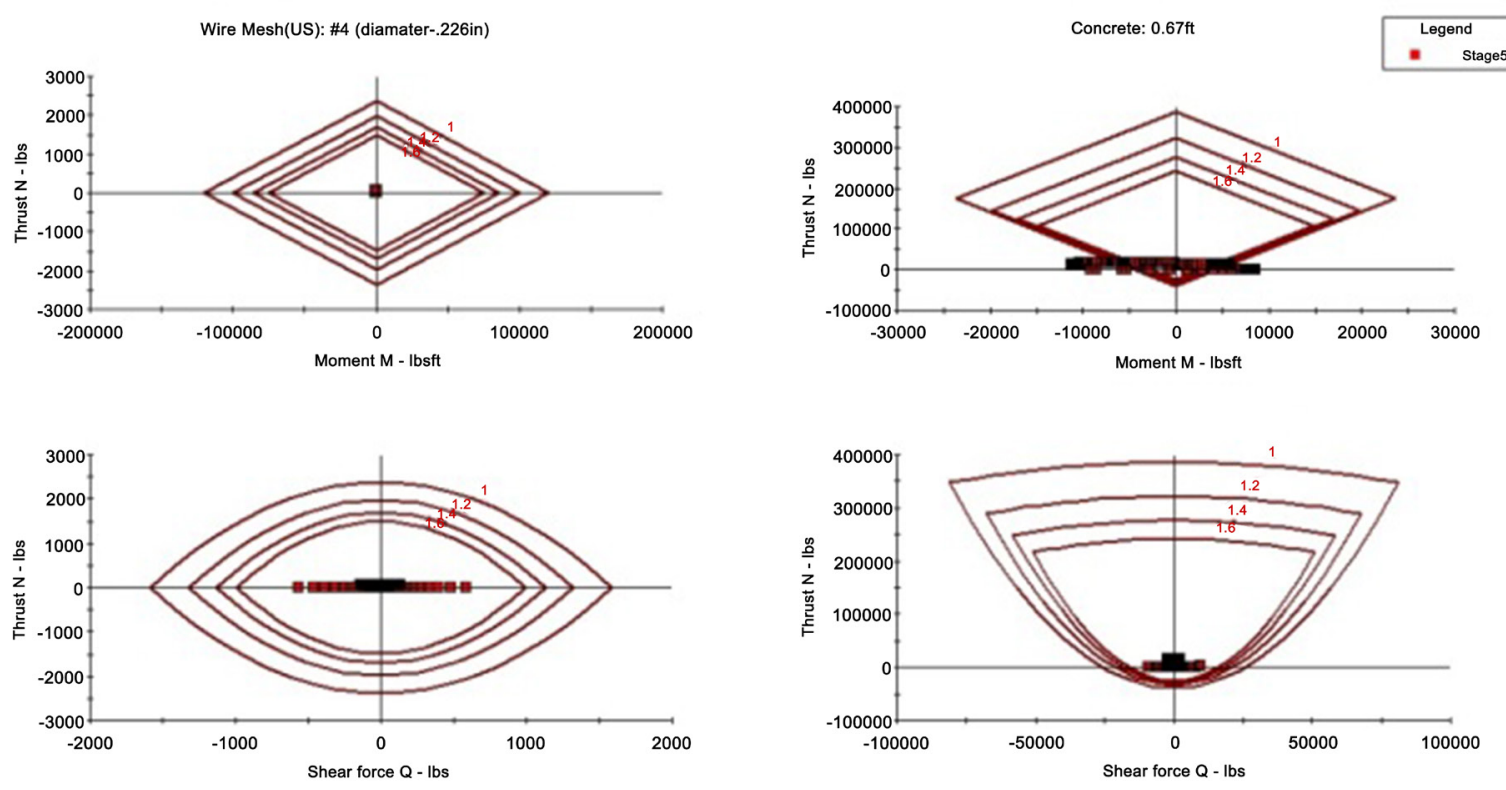

Support Element 8" liner

Figure 9. Shear/Moment Diagram Stage 4 
Table 2. Summary of Results

\begin{tabular}{|c|c|c|c|c|c|c|c|}
\hline \multirow{2}{*}{$\begin{array}{c}\text { Excavation } \\
\text { Stage }\end{array}$} & $\begin{array}{c}\text { Soil Vertical } \\
\text { Displacement } \\
(\mathrm{m})\end{array}$ & $\begin{array}{c}\text { Liner } \\
\text { Thickness } \\
(\mathrm{cm})\end{array}$ & $\begin{array}{c}\text { Layers of } \\
\text { Reinforcement }\end{array}$ & $\begin{array}{c}\text { FOS } \\
\text { Reinforcement } \\
\text { Shear }\end{array}$ & $\begin{array}{c}\text { FOS } \\
\text { Reinforcement } \\
\text { Moment }\end{array}$ & $\begin{array}{c}\text { FOS Liner } \\
\text { Shear }\end{array}$ & $\begin{array}{c}\text { FOS Liner } \\
\text { Moment }\end{array}$ \\
\hline 0 & 1.524 & N/A & N/A & N/A & N/A & N/A & N/A \\
\hline 1 & 0.26 & 5.08 & N/A & FOS $<1$ & FOS $<1$ & FOS $<1$ & FOS $<1$ \\
\hline 2 & 0.2 & 10.16 & 1 & FOS $>1$ & FOS $<1$ & FOS $<1$ & FOS $<1$ \\
\hline 3 & 0.1 & 15.24 & 2 & FOS $>1.4$ & FOS $>1.4$ & FOS $>1.4$ & FOS $>1.0$ \\
\hline 4 & 0.03 & 20.32 & 2 & FOS $>1.6$ & FOS $>1.6$ & FOS $>1.6$ & FOS $>1.5$ \\
\hline
\end{tabular}

\subsection{Fallout Using Cellular Concrete Model}

Phase 2 modeling was performed on the fallout condition at Oak Mountain Winery using a $2 \mathrm{D}$ cross section of the fallout repair area. Although 3D modeling will provide more accurate results, this study only utilized 2D modeling due to time constraints, availability of modeling software and budget. For the model, a 5.49 meters width by 3.05 meters high region was created to simulate the cellular concrete installed in the fallout section at the tunnel crown. The same properties for the soil as stated above were used. The cellular concrete had a unit weight of $23.6 \mathrm{kN} / \mathrm{m} 3$ and compressive strength of 1.72 $\mathrm{MPa}$. The following figures are the results from Phase 2.

Figure 10 was modeled for a 6.1 meters wide tunnel and the utilization of cellular concrete to support the fall out above Tunnel A with no liner. This shows the factor of safety values are well above 1 and the soil conditions are stable. Figure 11 indicates the maximum shear strain at the tunnel crest with the use of cellular concrete is zero. Since no shear strain is computed, this indicates the side friction of the geological material in the walls adjacent to the cellular concrete is sufficient.

\section{Discussion}

The foregoing analysis is an oversimplification of the actual sequential excavation that occurred at the project site. It should be noted, some points of the model results indicate factors of safety less than one. This represents tunneling corner conditions where a $2 \mathrm{D}$ model indicated high corner stress; hence, a lower factor of safety for some results for shear and moment diagrams. For more realistic results in tunnel corners, the authors suggest using a 3D finite element numerical modeling program. The analysis assumes that the entire tunnel length would be represented by one uniform liner type. This does not represent the sequential excavation and support construction that has proved successful in straight tunnels (thus far) when liner support closely follows excavation without the loss of wall liner where perpendicular tunnel advancement begins. This condition (perpendicular advancement) was the condition which was present at the time of the fallout. While displacements for Stages 1 and 2 indicate that some small amount $(20.3 \mathrm{~cm})$ of deflection will occur, the calculations indicate that until Stage 3 is provided, an acceptable factor of safety is not achieved for the structural liner. Therefore, the sequential excavation will require augmentation of additional temporary support for the length of excavated tunnel between the working face and Stage 3 liner construction. Figure 12 below shows the updated sequential method based on soil stand up time experienced in the field.

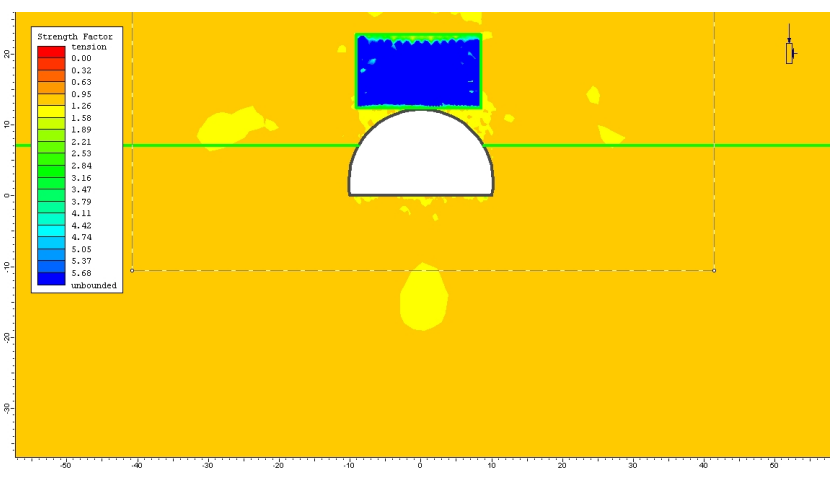

Figure 10. Strength factor (FOS) of soil with installed cellular concrete 6.1 meters wide tunnel

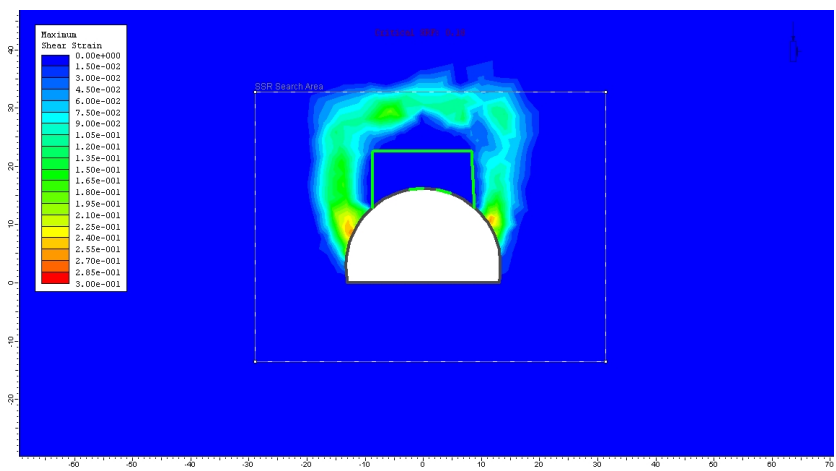

Figure 11. Maximum shear strain results for a 6.1 meters wide tunnel with no liner and cellular concrete installed 


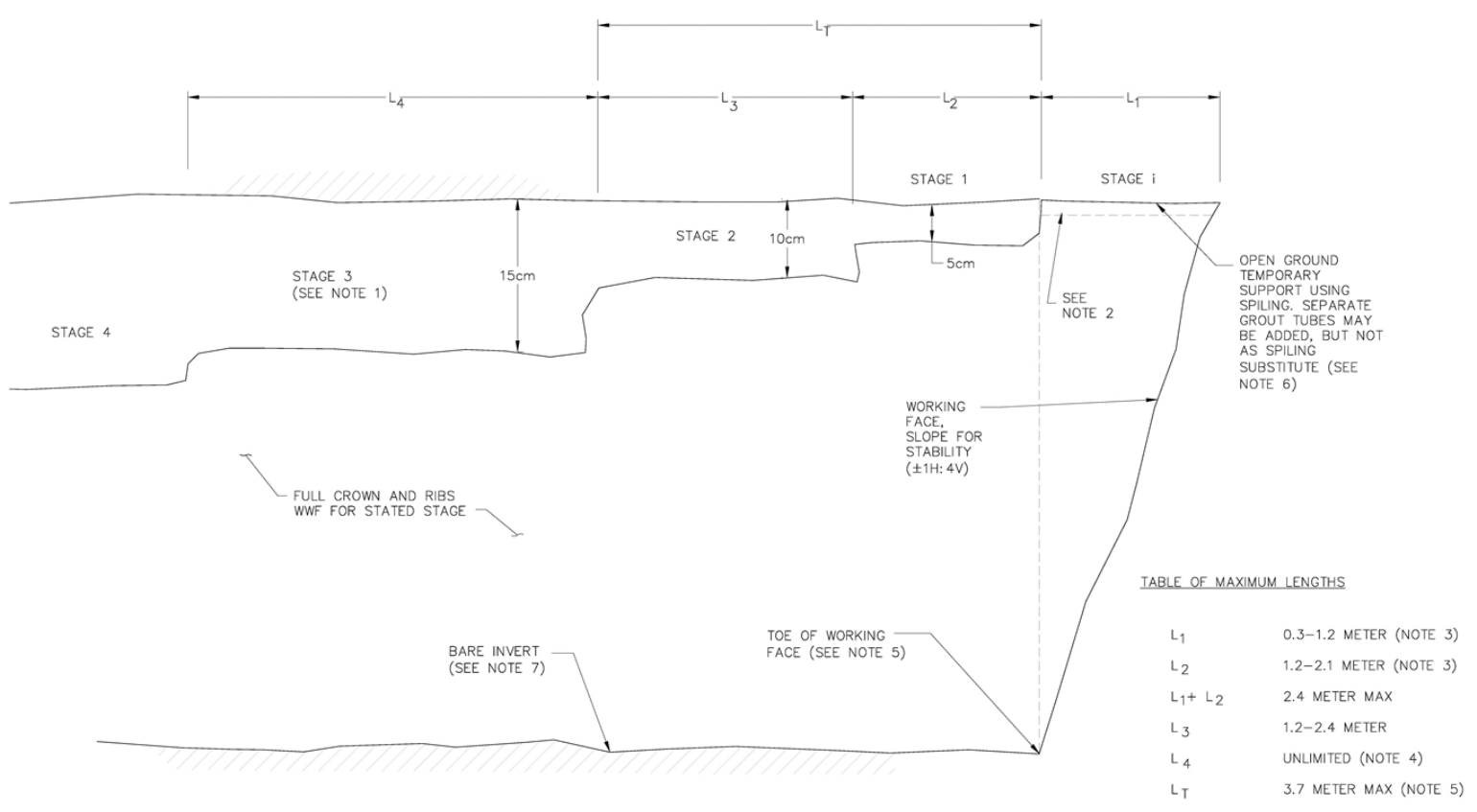

Figure 12. Updated sequential excavation plan for sandy soil conditions

For purposes of this review, a spiling detail (Figure 13) was developed with the contractor to incorporate this sequential excavation method to provide temporary support of the working face and the Stage 1 and Stage 2 areas. Strict adherence to the provided plans designating the maximum lengths for various stages was achieved to meet the stated factor of safety for Stage 3 liner. If the contractor was unable to meet the requirements of the provided plans for Temporary Support using the sequential excavations and spiling details, other means of temporary support were used, such as shielding, temporary steel sets, shotcrete-infilled steel sets, or other approved method. In the case of Stage 1 shotcrete, $\# 6$ rebars spaced $15.24 \mathrm{~cm}(6$ in). on center in sandy zones (less than $20 \%$ passing no. 200 sieve) were utilized for spiling until stable tunneling conditions were encountered.

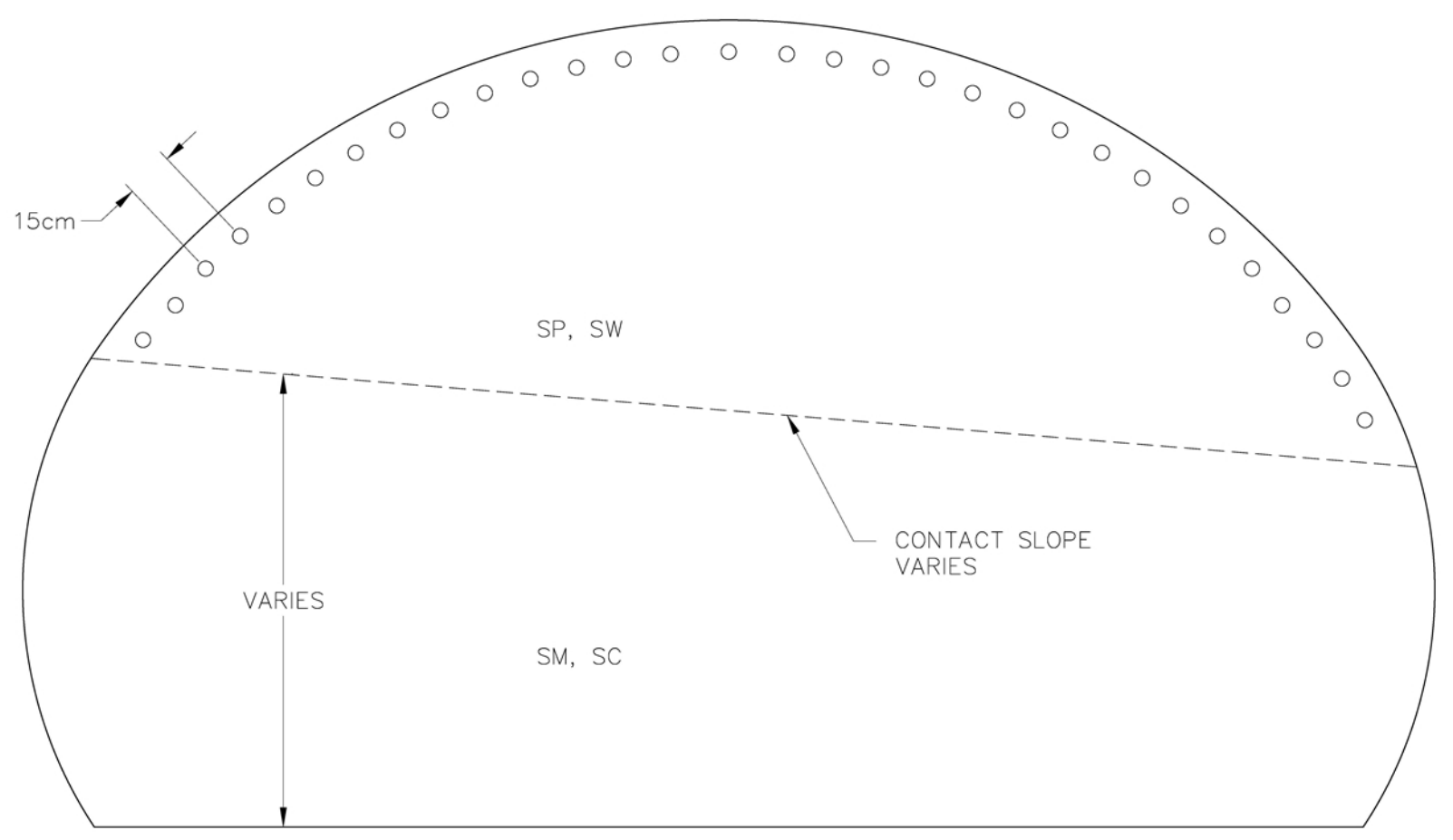




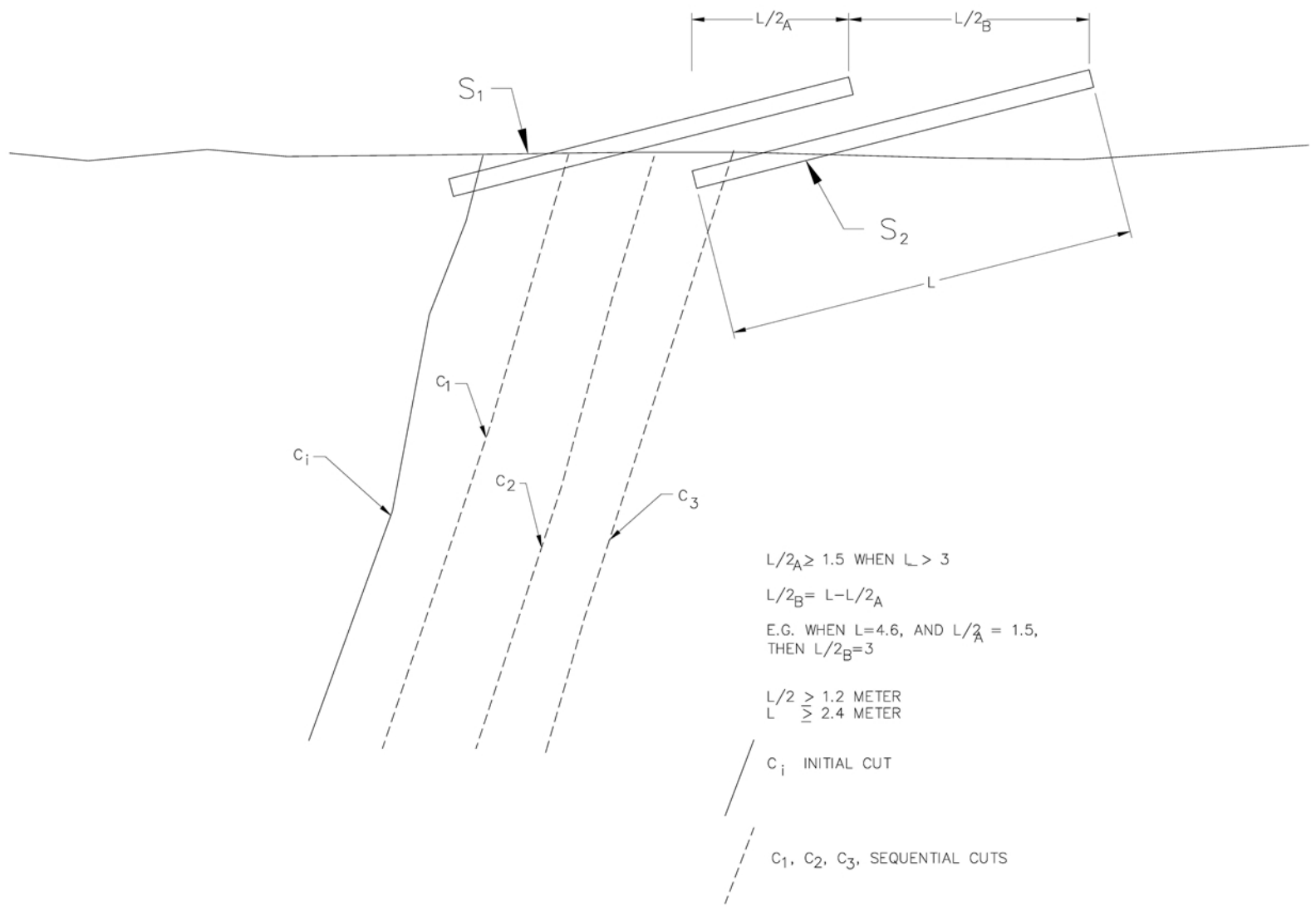

Figure 13. Spilling detail for tunnel crown

\section{Conclusions}

In summary, this paper was created from a general interest and professional experience for shallow tunneling in sandy soil conditions. The findings in this paper were used to exhibit successful method and analyses and may be advantageous in different mining scenarios. These key points are recommendations by the authors:

- Inexperienced or untrained personnel should receive training for dealing with unstable tunnel conditions and safety procedures if there is even the slightest probability that unstable conditions will be encountered;

- Always be aware of your surrounding and be conscious of unstable ground;

- Site investigation personnel should pay close attention to the local geology and ground conditions revealed by exploratory borings;

- $\quad$ Staged excavations should be considered if sandy soil is encountered;

- $\quad$ The use of cellular concrete proved to be worthy for fallout repair from both numerical modeling and site observations;

- The repair system conceived proved to be successful

- It would be beneficial to analyze the interaction of cellular concrete and the adjacent geological material using 3D numerical modeling
- Modeling can be used to estimate and for show if certain excavation methods will have the potential to succeed

The paper was constructed to help engineers, drillers and geologists better understand potentially unstable ground and how to determine which numerical and construction methods are the most appropriate for fallout situation as well as safe methods to continue tunneling. The methods discussed have shown great potential towards safe working areas in poor, sandy ground conditions when implemented successfully tunneling crews

\section{Acknowledgements}

The authors would like to show appreciation for Stephen and Valerie Andrews, owners of Oak Mountain Winery, for allowing us the opportunity to submit this paper. Without their help and understanding, this paper would not have been successfully completed. The authors would also like to express great thanks to all the workers at Magorian Mining Services of Auburn, CA USA most notably Don Magorian who was the tunneling contractor for the project. Magorian kept us on track and helped us succeed through the project end. 


\section{REFERENCES}

[1] Lee CJ., Chiang, K.H. \& Kuo, C.H. (2004) Ground movement and tunnel stability when tunneling in sandy ground, Journal of the Chinese Institute of Engineers, 27:7, 1021-1032

[2] Chen, B. and Hsiung, B. (2011) A case record of bored tunnels in sand based on the kaohsiung mass rapid transit system project. Journal of GeoEngineering, Vol. 6, No. 3, pp. 113-123, December 2011

[3] J. H. Atkinson and D. M. Potts, "Stability of a shallow circular tunnel in cohesionless soil," Géotechnique, vol. 27, no. 2, pp. 203-215, 1977

[4] Hamad, A. J. (2014) Materials, Production, Properties and Application of Aerated Lightweight Concrete: Review. International Journal of Materials Science and Engineering Vol. 2, No. 2 December 2014

[5] Kim, H.K., Jeon, J.H., and Lee, H.K. (2012).Workability, and mechanical, acoustic and thermal properties of lightweight aggregate concrete with a high volume of entrained air. Journal of Construction and Building Materials, Volume 29, April 2012. Pp. 193-200
[6] Condor Earth Technologies, Inc. (2013), Geotechnical Engineering Study, Wine Cave Facilities, Oak Mountain Winery, 36522 Via Verde, Temecula, CA, April 22, 2013

[7] Rocscience, Inc. 2011. Phase2 (Finite Element Analysis for Excavations and Slopes)Version 8.0.Rocscience. Toronto, Canada.

[8] Technical Manual for design and construction of road tunnels- civil elements, Report No. FHWAA-NHI-10-034, Federal Highway Administration, 2009

[9] Sheorey, P.R., (1994), A Theory for In Situ Stresses in Isotropic and Transversely Isotropic Rock. Int. J. Rock Mech. Min. Sci \& Geomech. Abstr. 31(1), 23-34

[10] Vlachopoulos, N. and Diederichs, M.S. (2009). Improved longitudinal displacement profiles for convergence-confinement analysis of deep tunnels. Rock Mechanics and Rock Engineering, Volume 42, Issue 2, pp. 131-14

[11] Barton, N.R., Lien, R. and Lunde, J. (1974). Engineering classification of rock masses for the design of tunnel support. Rock Mech. 6(4), 189-239 